\title{
Neutral cervical sagittal vertical axis and cervical lordosis vary with T1 tilt
}

\author{
Ryan C. Hofler, MD, MS, ${ }^{1}$ Muturi G. Muriuki, PhD, ${ }^{2}$ Robert M. Havey, MS, ${ }^{2}$ \\ Kenneth R. Blank, PhD, MHA, ${ }^{2}$ Joseph N. Frazzetta, BS, ${ }^{3}$ Avinash G. Patwardhan, $\mathrm{PhD},{ }^{2}$ and \\ G. Alexander Jones, MD'
}

\begin{abstract}
'Department of Neurological Surgery, Loyola University Stritch School of Medicine, Maywood; ${ }^{2}$ Musculoskeletal Biomechanics Laboratory, Research Service, Edward Hines Jr. VA Hospital, Hines; and ${ }^{3}$ Loyola University Stritch School of Medicine, Maywood, Illinois
\end{abstract}

OBJECTIVE The authors conducted a study to determine whether a change in T1 tilt results in a compensatory change in the cervical sagittal vertical axis (SVA) in a cadaveric spine model.

METHODS Six fresh-frozen cadavers (occiput [C0]-T1) were cleaned of soft tissue and mounted on a customized test apparatus. A 5-kg mass was applied to simulate head weight. Infrared fiducials were used to track segmental motion. The occiput was constrained to maintain horizontal gaze, and the mounting platform was angled to change T1 tilt. The SVA was altered by translating the upper (occipital) platform in the anterior-posterior plane. Neutral SVA was defined by the lowest flexion-extension moment at $\mathrm{T} 1$ and recorded for each $\mathrm{T} 1$ tilt. Lordosis was measured at C0-C2, C2-7, and C0-C7.

RESULTS Neutral SVA was positively correlated with T1 tilt in all specimens. After increasing T1 tilt by a mean of $8.3^{\circ}$ $\pm 2.2^{\circ}$, neutral SVA increased by $27.3 \pm 18.6 \mathrm{~mm}$. When T1 tilt was reduced by $6.7^{\circ} \pm 1.4^{\circ}$, neutral SVA decreased by a mean of $26.1 \pm 17.6 \mathrm{~mm}$.

When T1 tilt was increased, overall (CO-C7) lordosis at the neutral SVA increased from $23.1^{\circ} \pm 2.6^{\circ}$ to $32.2^{\circ} \pm 4.4^{\circ}(p$ $<0.01)$. When the T1 tilt decreased, $\mathrm{C} 0-\mathrm{C} 7$ lordosis at the neutral SVA decreased to $15.6^{\circ} \pm 3.1^{\circ}(\mathrm{p}<0.01)$. C0-C2 lordosis increased from $12.9^{\circ} \pm 9.3^{\circ}$ to $29.1^{\circ} \pm 5.0^{\circ}$ with increased T1 tilt and decreased to $-4.3^{\circ} \pm 6.8^{\circ}$ with decreased T1 tilt ( $p=0.047$ and $p=0.041$, respectively).

CONCLUSIONS Neutral SVA is not a fixed property but, rather, is positively correlated with T1 tilt in all specimens. Overall lordosis and $\mathrm{C} 0-\mathrm{C} 2$ lordosis increased when T1 tilt was increased from baseline, and vice versa.

https://thejns.org/doi/abs/10.3171/2020.2.SPINE191363

KEYWORDS sagittal vertical axis; lordosis; cervical spine; T1 tilt; deformity

$\mathrm{O}$ VER the last 2 decades, an increase in our understanding of sagittal balance has dramatically changed the way spine surgeons practice in the United States and abroad. This occurred first with research on spinopelvic parameters and overall sagittal balance, followed by studies establishing normative values for asymptomatic patients. ${ }^{1,2}$ In the last decade, an emerging interest in cervical sagittal balance, as a separate entity, has taken hold.

Knott and colleagues first described T1 tilt in $2010,{ }^{3}$ and this, both literally and figuratively, formed the foundation for much of the work that followed. While the relationship between T1 tilt and the cervical sagittal vertical axis (CSVA) has been described more recently in the clinical literature, ${ }^{4-6}$ no biomechanical study exists, to date, to describe this dynamic interaction. Thus, we conducted a study to determine whether a change in $\mathrm{T} 1$ tilt results in a compensatory change in the CSVA in a cadaveric spine model.

\section{Methods}

\section{Specimen Preparation}

The experiments were performed using 6 fresh-frozen human cadaveric cervical spine specimens (occiput-T1) (Table 1). The muscle tissues were dissected, while keeping the discs, ligaments, and posterior bony structures intact. Specimen-specific anatomical and kinematic models were built for each specimen to facilitate analysis of the experimental data. ${ }^{7.8}$ For this purpose, 5 aluminum radi- 
TABLE 1. Specimen demographics

\begin{tabular}{ccc}
\hline Specimen No. & Age (yrs) & Sex \\
\hline 1 & 38 & $\mathrm{~F}$ \\
\hline 2 & 52 & $\mathrm{~F}$ \\
\hline 3 & 39 & $\mathrm{~F}$ \\
\hline 4 & 45 & $\mathrm{M}$ \\
\hline 5 & 49 & $\mathrm{M}$ \\
\hline 6 & 54 & $\mathrm{M}$ \\
\hline
\end{tabular}

The specimens were a mean age of $46.2 \pm 6.7$ years at the time of death.

opaque spheres were embedded in the occiput and each vertebra from $\mathrm{C} 1$ to $\mathrm{T} 1$. Fine-slice axial $\mathrm{CT}$ scans of the specimens were obtained prior to experiments.

\section{Experimental Setup}

A novel test apparatus was designed to study the biomechanical consequences of cervical sagittal imbalance on the mechanics of the cervical spine. ${ }^{8,9}$ The apparatus allows independent, controlled adjustment of the T1 tilt angle and anterior head offset relative to the base of the cervical spine (Fig. 1 left). The specimen was mounted in the apparatus with the T1 vertebra anchored to a translating base. The occiput was free to move vertically, but its angular orientation was constrained to preserve horizontal gaze, regardless of simulated imbalance. ${ }^{9}$ The Frankfort plane (a line connecting the external auditory meatus with the inferior orbital rim) defined horizontal gaze. A 5-kg mass was attached to the occiput to mimic head weight.

\section{Measurement Techniques}

To assess 3D vertebral motions, infrared targets were rigidly attached to the occiput and each vertebral body using threaded rods (Fig. 1 right). The targets were tracked using an optoelectronic motion measurement system (Optotrak Certus, Northern Digital). A stationary target that defines the specimen's anatomical coordinate system was mounted at the base of the apparatus. The input displacements at the base (CSVA and T1 tilt) were measured using infrared targets (Fig. 2).

The forces and moments at the base of the spine were measured using a 6-component load cell (Model MC3A6-250, AMTI Inc.) placed under the specimen. This load cell measured the head-weight force applied to the occiput, reaction forces generated at the cranial bearing, and the resultant moment at the base.

\section{Experimental Protocol}

The magnitude of occiput (C0)-C7 SVA was increased and motions of $\mathrm{Cl}-7$ vertebrae measured to document the postural consequences of sagittal imbalance. The test was stopped when the flexion or extension moment measured at the load cell placed beneath $\mathrm{T} 1$ reached a limit of $3 \mathrm{Nm}$. This stopping criterion minimizes the risk of soft-tissue damage that may occur due to repeated loading during testing. ${ }^{10,11}$ The test was conducted with the T1 tilt set at 3 different values. These were a nominal (or initial) T1 tilt angle, a T1 tilt angle increased above nominal, and a T1 tilt angle reduced below nominal.

\section{Measurements}

We defined a zero (or lowest-magnitude) T1 flexionextension moment as the neutral CSVA. This serves as a criterion by which to understand postural consequences, as this simulates the head and neck position requiring the least muscle contraction to maintain.

The CSVA at which the T1 flexion-extension moment was zero (or at a minimum value) was determined for each of the 3 CSVA tests conducted. The lordosis angles and foraminal heights at these lowest energy states were calculated from lines and points defined on the specimen's CT-derived anatomy. The motion and orientation of these lines and points during the test were determined using the specimen-specific anatomical and kinematic modeling technique. ${ }^{7,8}$

\section{Lordosis Angle}

C2-7 lordosis was the angle between anterior-posterior lines drawn on the superior surfaces of the $\mathrm{C} 2$ and $\mathrm{C} 7$ vertebral bodies. The same lines on $\mathrm{C} 2$ and $\mathrm{C} 7$ were used to determine $\mathrm{C} 0-\mathrm{C} 7, \mathrm{C} 0-\mathrm{C} 2$ lordosis. The $\mathrm{C} 0$ line used to calculate these two lordosis angles was the Frankfort horizontal plane. ${ }^{12}$

\section{Foraminal Height}

Foraminal height was the vertical distance between two points at the isthmus of the neural foramen. These are a point on the lower arch in the superior vertebral body and a point on the upper arch of the inferior vertebral body. Foraminal height was calculated for the left and right neural foramina from $\mathrm{C} 3-4$ to $\mathrm{C} 7-\mathrm{T} 1$.

\section{Results}

\section{Neutral CSVA and T1 Tilt}

Neutral CSVA was positively correlated with $\mathrm{T} 1$ tilt in all specimens. After increasing T1 tilt by $8.3^{\circ} \pm 2.2^{\circ}$, the neutral CSVA point moved anteriorly (increased) by 27.3 $\pm 18.6 \mathrm{~mm}$. When the T1 tilt was reduced by $6.7^{\circ} \pm 1.4^{\circ}$, neutral SVA decreased (was posterior of the nominal) by $26.1 \pm 17.6 \mathrm{~mm}$. While the magnitude of this change was different from one specimen to another, the direction of this change, both when increasing and decreasing T1 tilt, was the same for every specimen (Fig. 3).

\section{Lordosis and T1 Tilt at Neutral CSVA}

When $\mathrm{T} 1$ tilt was increased (Fig. 4), overall $(\mathrm{C} 0-\mathrm{C} 7)$ lordosis at neutral SVA increased from $23.1^{\circ} \pm 2.6^{\circ}$ to $32.2^{\circ} \pm 4.4^{\circ}(\mathrm{p}<0.01$, t-test, two-tailed, paired with Bonferroni correction for multiple comparisons). When T1 tilt decreased, C0-C7 lordosis at neutral SVA also decreased to $15.6^{\circ} \pm 3.1^{\circ}$ ( $p<0.01$, t-test, two-tailed, paired with Bonferroni correction for multiple comparisons).

Upper cervical lordosis at neutral SVA, likewise, increased with T1 tilt (Fig. 5). C0-C2 lordosis increased from $12.9^{\circ} \pm 9.3^{\circ}$ to $29.1^{\circ} \pm 5.0^{\circ}$ with increased T1 tilt and decreased to $-4.3^{\circ} \pm 6.8^{\circ}$ with decreased T1 tilt $(\mathrm{p}=0.041$ 

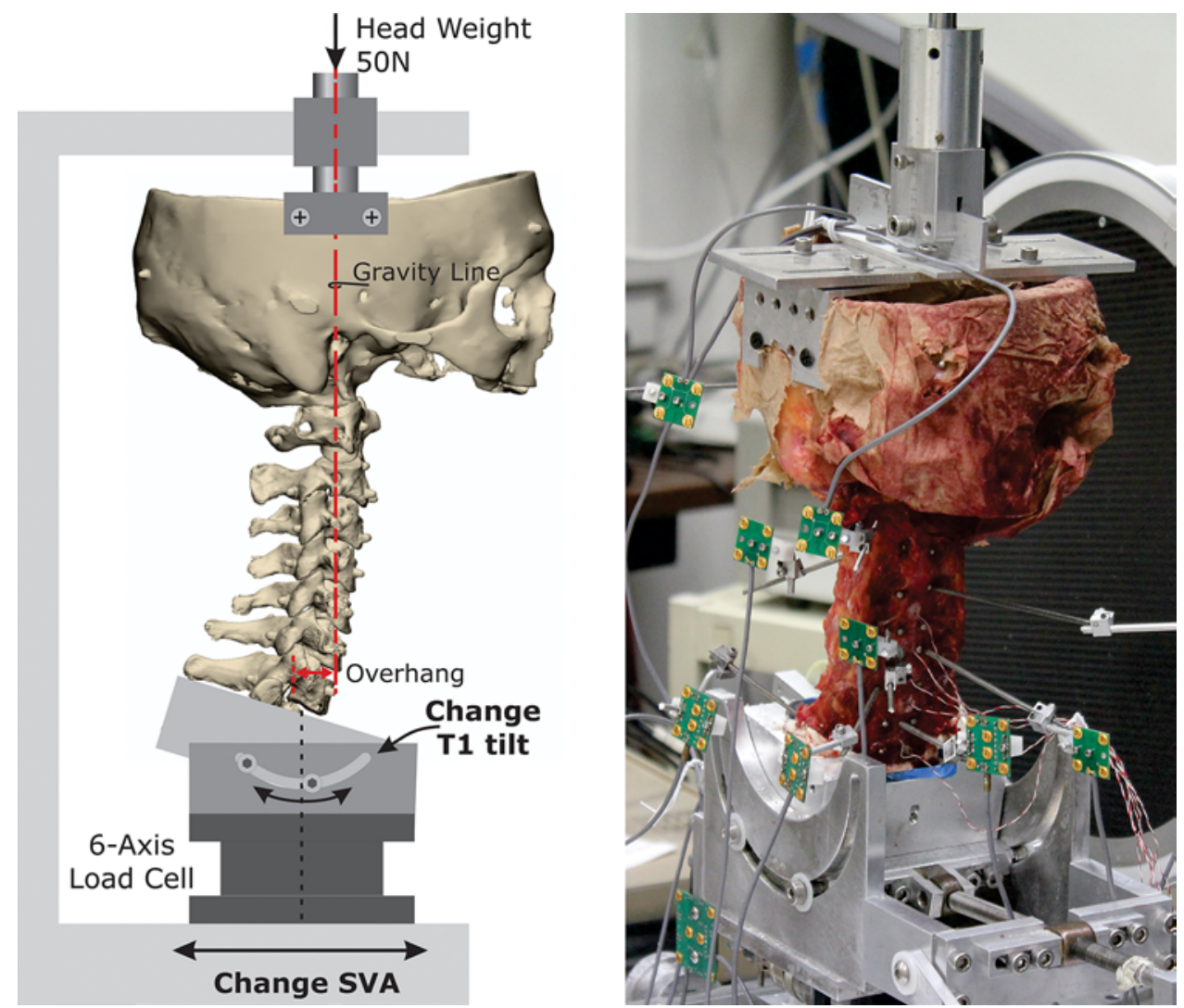

FIG. 1. Experimental setup. Figure is available in color online only.

and $\mathrm{p}=0.047$, respectively; t-test, two-tailed, paired with Bonferroni correction for multiple comparisons).

Here, again, while the magnitude of change varied by specimen, the direction of change was consistent across all specimens. When evaluated at neutral SVA, an increase in $\mathrm{T} 1$ tilt led to an increase in lordosis at $\mathrm{C} 0-\mathrm{C} 7$ and at $\mathrm{C} 0$ $\mathrm{C} 2$. In general, the lordosis change was larger at $\mathrm{C} 0-\mathrm{C} 2$ than at $\mathrm{C} 0-\mathrm{C} 7$, resulting in a decrease in lordosis at $\mathrm{C} 2-7$.

\section{Foraminal Height and T1 Tilt at Neutral SVA}

At neutral SVA, there were only slight changes in measured neural foramen height (Fig. 6). These changes were, on average, less than a millimeter. At neutral SVA with reduced T1 tilt, compared to the nominal T1 tilt, there was a reduction in overall foraminal height from $\mathrm{C} 3-4$ to $\mathrm{C} 7-$ T1. There was no such pattern found in foraminal height at neutral SVA with increased T1 tilt. Compared to the nominal $\mathrm{T} 1$ tilt angle, with increased $\mathrm{T} 1$ tilt, the foraminal height was the same or increased at $\mathrm{C} 3-4, \mathrm{C} 4-5$, and C6-7. Under these same conditions (increased T1 tilt and neutral SVA), foraminal height was reduced at C5-6 and C7-T1.

\section{Discussion}

A key relationship emerges from these data: Neither SVA nor overall lordosis is a fixed property; rather, both vary with the external influence of T1 tilt. Understanding the clinical importance of T1 tilt is fundamental to un-

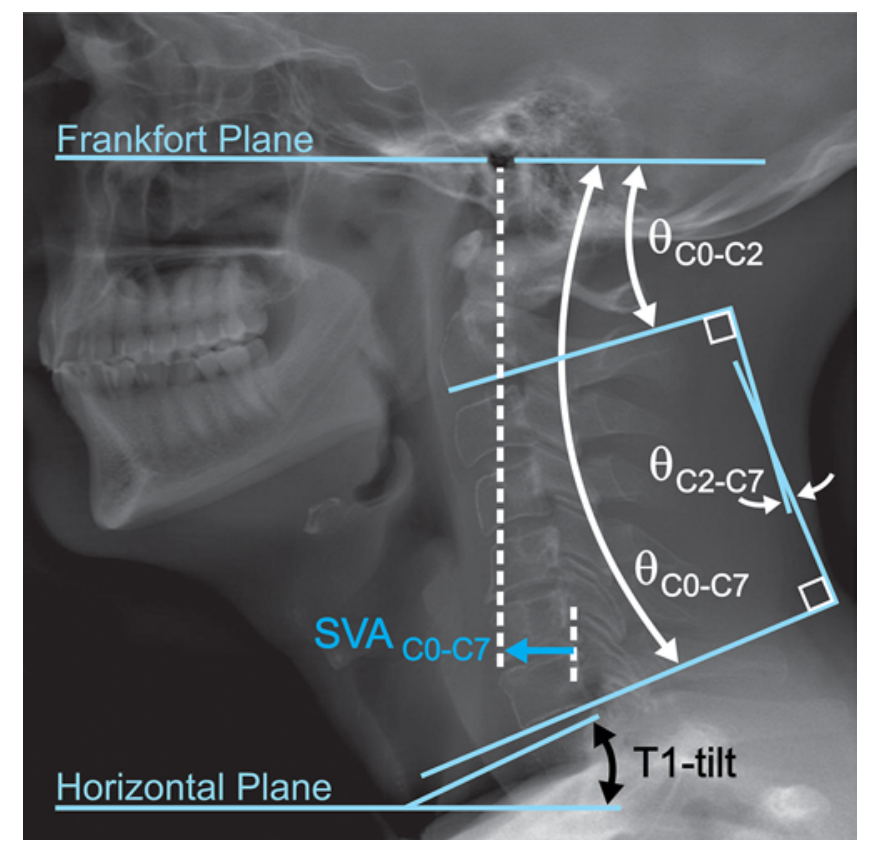

FIG. 2. Illustration of measurements. Figure is available in color online only. 
Specimen 1 OSpecimen $2 \square$ Specimen $3 \quad$ XSpecimen $4 \quad$ xSpecimen $5 \Delta$ Specimen 6

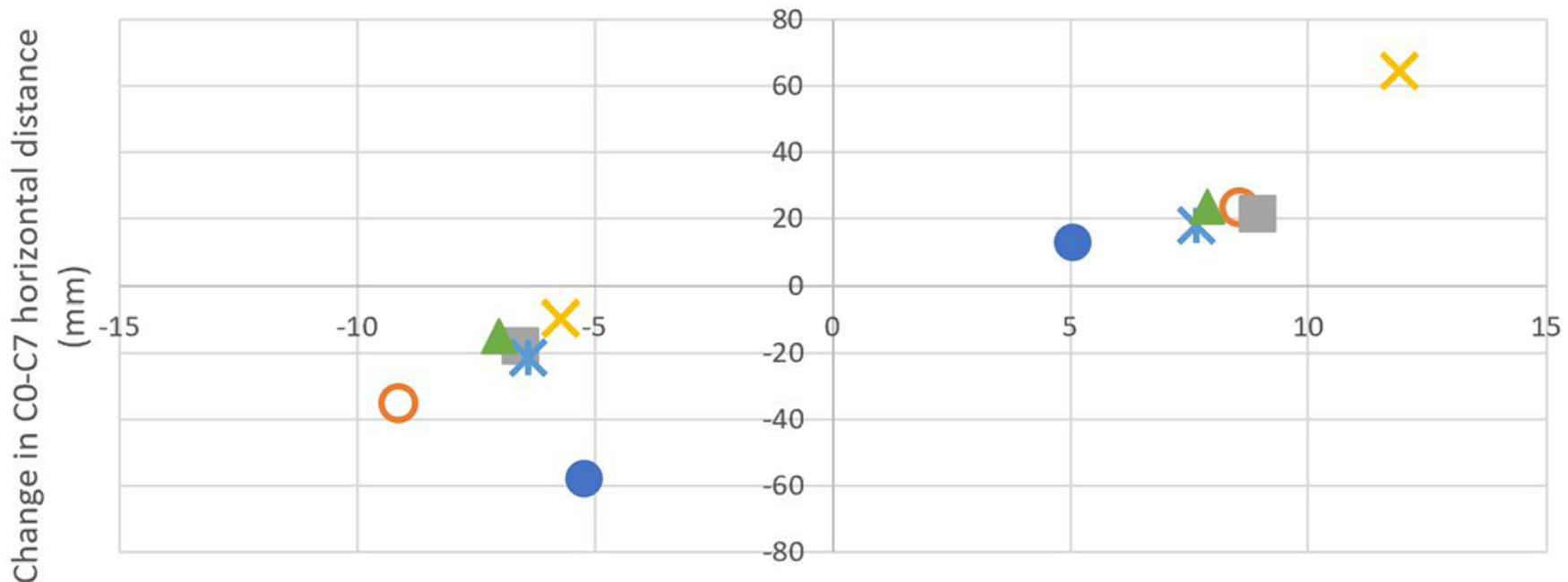

\section{Change in T1 tilt from Nominal (degrees)}

FIG. 3. Change in SVA with respect to change in T1 tilt. Figure is available in color online only.

derstanding cervical sagittal balance. Just as sacral slope and pelvic incidence predict neutral lumbar posture, so too does T1 tilt predict neutral cervical posture. ${ }^{13}$

Several radiographic studies have shown this as well. Akbar and colleagues investigated cervical sagittal balance in the setting of adolescent idiopathic scoliosis. ${ }^{14}$ For those with thoracic hypokyphosis resulting in a low T1 tilt, CSVA was lower than it was in those without thoracic hypokyphosis. In several other studies, ${ }^{4-6} \mathrm{~T} 1$ tilt has been shown to increase with age. One of these studies ${ }^{4}$ showed an increase in both T1 tilt and CSVA in asymptomatic patients, with increasing age. Studying adult spinal deformity patients, Staub and colleagues noted a correlation between T1 tilt and cervical lordosis. They defined the relationship with a linear equation, with normative cervical lordosis equal to $\mathrm{T} 1$ slope minus $16.5^{\circ} .15$

In our study, T1 tilt was used as the independent variable, and CSVA and lordosis were measured as the dependent variables. In vivo, this relationship is more dynamic. While T1 tilt likely has a commanding influence on cervi-

\section{CO-C7 Lordosis Angle}

\section{All Specimens $\square$ Specimen 1 Specimen 2 Specimen $3 \quad$ Specimen 4 Specimen $5 \square$ Specimen 6} 50

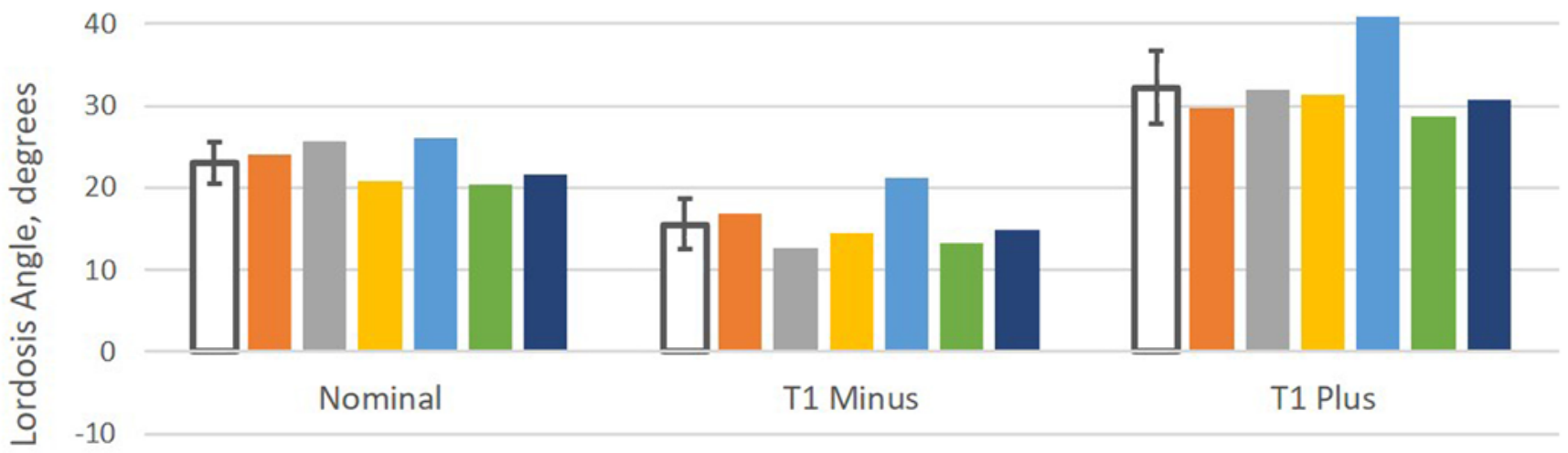

$-20$

FIG. 4. Change in overall lordosis with T1 tilt. Figure is available in color online only. 
C0-C2 Lordosis Angle

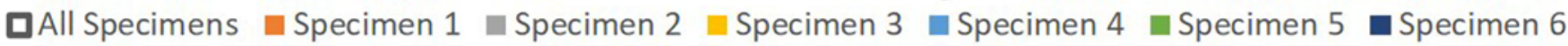
40

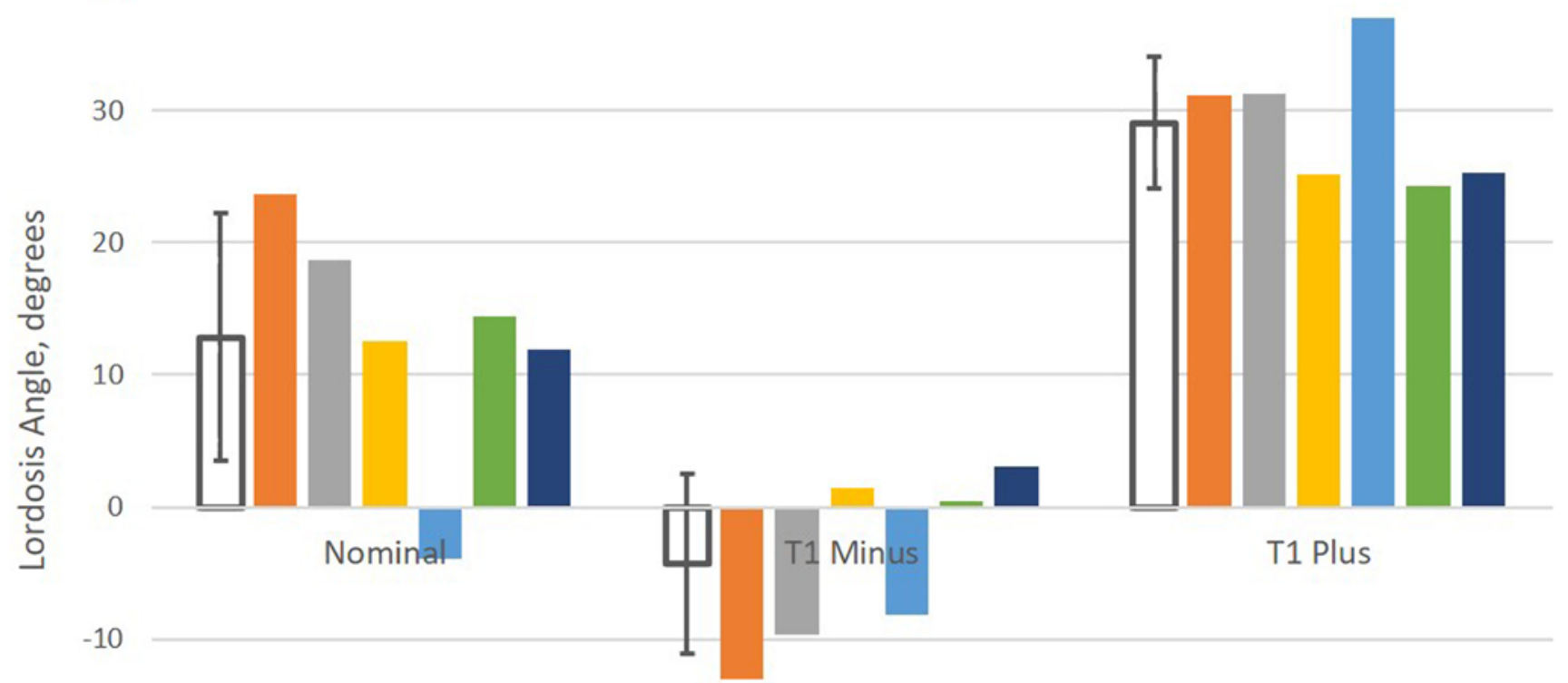

T1 Tilt During SVA Test

FIG. 5. Change in upper cervical lordosis with T1 tilt. Figure is available in color online only.

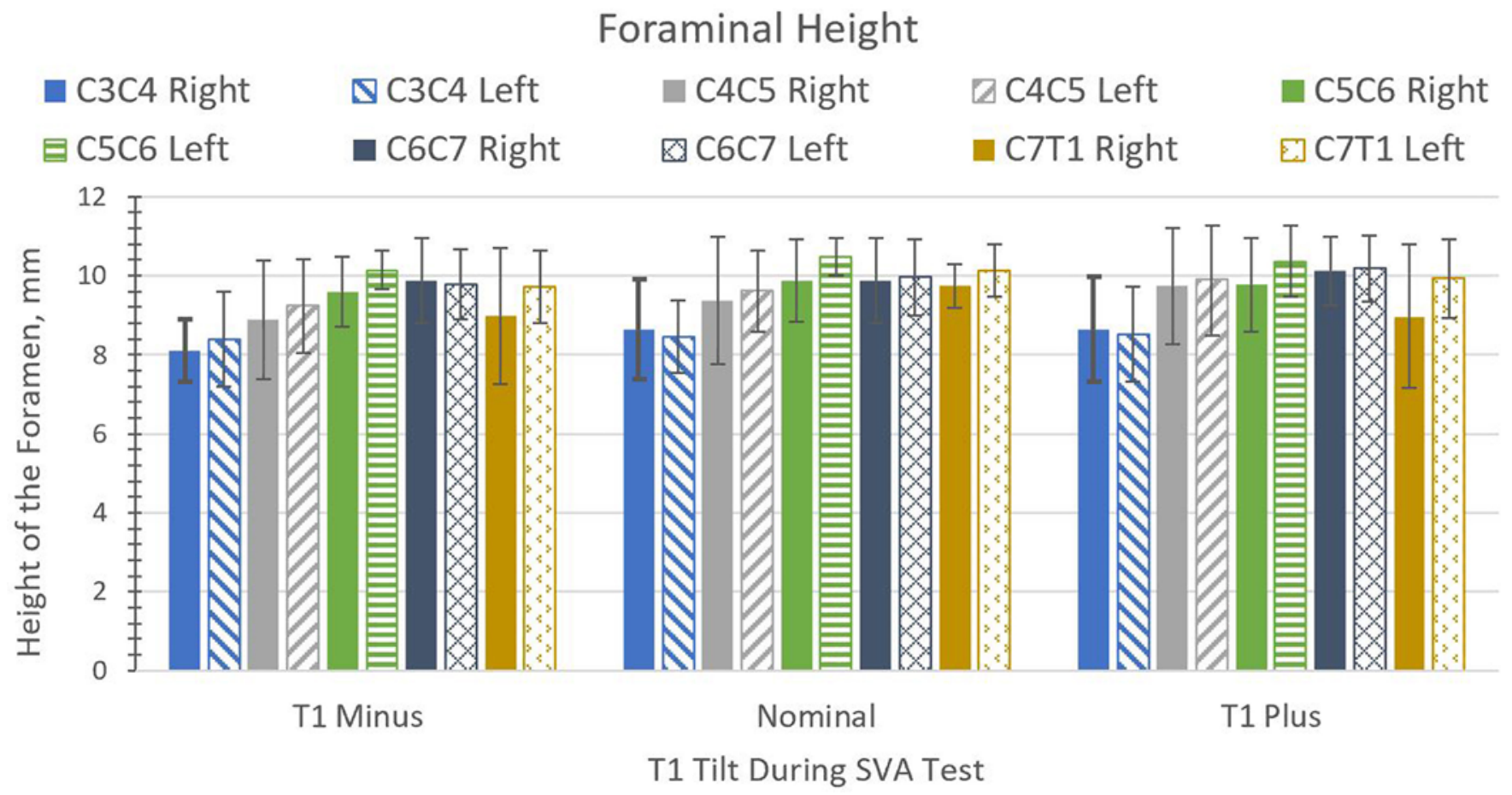

FIG. 6. Change in foraminal height with T1 tilt. Figure is available in color online only. 
cal alignment simply because our posture is defined from the ground up, T1 tilt can also change, via alterations in thoracic kyphosis, in response to changes in cervical alignment. Looking at patients who had undergone surgical correction of cervical kyphosis, Lee and colleagues found that such correction resulted in an increase in both $\mathrm{T} 1 \mathrm{tilt}$ and thoracic kyphosis but no change in other spinopelvic parameters. ${ }^{16}$ The implication is that patients with cervical kyphosis (or hypolordosis) will maintain horizontal gaze by contracting their extensor musculature, thus reducing thoracic kyphosis and T1 tilt. This allows the hypolordotic cervical spine to rest on a platform that is closer to horizontal. Once the cervical deformity is corrected, the thoracic spine can regain its natural kyphosis, and $\mathrm{T} 1$ tilt increases.

Of course, these population-based studies can only look at snapshots of different patients at different ages, raising the question of sampling error. To truly confirm the gradual increase of T1 tilt and CSVA with age would require a longitudinal cohort study. This is not only challenging from a logistical and cost standpoint but from a practical one as well: Our definitions of these cervical sagittal balance parameters have just now been around long enough that a cohort from an early study might show significant radiographic changes on a current investigation.

While a longitudinal cohort study might be on (or still over) the horizon, the combination of several radiographic investigations showing an increase in T1 tilt and CSVA over time, along with the present data demonstrating the biomechanical relationship between these two parameters, strongly suggests that the two are interdependent.

Moreover, there is evidence that the reason CSVA varies with $\mathrm{T} 1$ tilt is to maintain a state requiring the least input of external energy. In asymptomatic patients, CSVA and T1 tilt increase concurrently; ${ }^{4}$ in our study, the neutral CSVA follows T1 tilt. Patients will only remain asymptomatic if they do not have to maintain continuous muscle contraction to hold their posture, and the neutral CSVA state in our experiment was defined as the position transferring the lowest rotational force (moment) to the mounting platform at T1, a laboratory simulation of the state requiring the least muscle tone to maintain. Thus, in both cases, this represents the lowest energy state.

Another potential positive effect of increasing CSVA with T1 tilt is evident. In a prior study, increased CSVA was shown to correlate with an increased cross-sectional surface area of the cervical foramina. ${ }^{8}$ The dependence of CSVA on T1 tilt is likely the result of loading the lowest cervical facets, and the increase in CSVA with T1 tilt will offer some protection against foraminal stenosis.

T1 tilt also influenced cervical lordosis, both globally $(\mathrm{C} 0-\mathrm{C} 7)$ and in the upper neck $(\mathrm{C} 0-\mathrm{C} 2)$. This is expected, as the specimen was fixed to maintain horizontal gaze, so that any increase in $\mathrm{T} 1$ tilt would necessarily require a compensatory increase in cervical lordosis. However, this is representative of the in vivo state, as patients with progressive thoracic kyphosis, and thus higher T1 tilt, will demonstrate increasing cervical lordosis in order to maintain horizontal gaze. ${ }^{4,6}$

Less clear is the relationship between T1 tilt, CSVA, and neck pain. There is evidence of T1 tilt and CSVA increasing with age in asymptomatic patients. ${ }^{4,17}$ However, several studies have shown an association between increased neck disability and higher CSVA, ${ }^{18}$ whereas lower neck disability was shown in patients with higher T1 tilt and lower CSVA. ${ }^{19}$ There appears to be a similar effect with degenerative changes: T1 tilt was higher, and CSVA lower, in the control group than in patients with degenerative changes. ${ }^{20}$ Following posterior cervical fusion, patients with greater disparity between T1 tilt and cervical lordosis had higher neck disability index scores. ${ }^{17}$ This underscores the idea that $\mathrm{T} 1$ tilt and cervical lordosis are linked, and that any iatrogenic disruption of this relationship will have clinical consequences.

At all events, our understanding of the complex interplay among these different parameters continues to grow. This study, taken with similar findings in radiographic and clinical studies, serves to clarify the relationship between T1 tilt and CSVA.

\section{Study Limitations}

While our experimental setup has been carefully designed to recreate physiological loads, it has not been independently validated, and there are limitations in such an ex vivo setup. The muscles have been removed, and cannot provide stabilizing force. Over the course of testing, ligaments and discs are subject to desiccation, in spite of careful efforts to prevent this. Due to the time and expense of an experiment like this, testing is generally limited to fewer than 10 specimens. These results may serve to bolster our understanding of biomechanics, and possibly guide further clinical inquiry, but extrapolating biomechanical data to guide clinical practice should only be done with great caution.

\section{Conclusions}

CSVA is dependent on T1 tilt. It increases with increasing T1 tilt, and decreases with decreasing T1 tilt.

Upper $(\mathrm{C} 0-\mathrm{C} 2)$ and overall $(\mathrm{C} 0-\mathrm{C} 7)$ cervical lordosis increase with increases in $\mathrm{T} 1 \mathrm{tilt}$, and vice versa, from baseline.

\section{References}

1. Iyer S, Lenke LG, Nemani VM, et al. Variations in sagittal alignment parameters based on age: a prospective study of asymptomatic volunteers using full-body radiographs. Spine (Phila Pa 1976). 2016;41(23):1826-1836.

2. Roussouly P, Gollogly S, Berthonnaud E, Dimnet J. Classification of the normal variation in the sagittal alignment of the human lumbar spine and pelvis in the standing position. Spine (Phila Pa 1976). 2005;30(3):346-353.

3. Knott PT, Mardjetko SM, Techy F. The use of the T1 sagittal angle in predicting overall sagittal balance of the spine. Spine J. 2010;10(11):994-998.

4. Attiah M, Gaonkar B, Alkhalid Y, et al. Natural history of the aging spine: a cross-sectional analysis of spinopelvic parameters in the asymptomatic population. J Neurosurg Spine. 2020;32(1):63-68.

5. Chen Y, Luo J, Pan Z, et al. The change of cervical spine alignment along with aging in asymptomatic population: a preliminary analysis. Eur Spine J. 2017;26(9):2363-2371.

6. Tang R, Ye IB, Cheung ZB, et al. Age-related changes in cervical sagittal alignment: a radiographic analysis. Spine (Phila Pa 1976). 2019;44(19):E1144-E1150. 
7. Havey RM, Goodsitt J, Khayatzadeh S, et al. Three-dimensional computed tomography-based specimen-specific kinematic model for ex vivo assessment of lumbar neuroforaminal space. Spine (Phila Pa 1976). 2015;40(14):E814-E822.

8. Smith ZA, Khayatzadeh S, Bakhsheshian J, et al. Dimensions of the cervical neural foramen in conditions of spinal deformity: an ex vivo biomechanical investigation using specimenspecific CT imaging. Eur Spine J. 2016;25(7):2155-2165.

9. Patwardhan AG, Havey RM, Khayatzadeh S, et al. Postural consequences of cervical sagittal imbalance: a novel laboratory model. Spine (Phila Pa 1976). 2015;40(11):783-792.

10. Lee MJ, Dumonski M, Phillips FM, et al. Disc replacement adjacent to cervical fusion: a biomechanical comparison of hybrid construct versus two-level fusion. Spine (Phila Pa 1976). 2011;36(23):1932-1939.

11. Martin S, Ghanayem AJ, Tzermiadianos MN, et al. Kinematics of cervical total disc replacement adjacent to a twolevel, straight versus lordotic fusion. Spine (Phila Pa 1976). 2011;36(17):1359-1366.

12. Madsen DP, Sampson WJ, Townsend GC. Craniofacial reference plane variation and natural head position. Eur J Orthod. 2008;30(5):532-540.

13. Weng C, Wang J, Tuchman A, et al. Influence of T1 slope on the cervical sagittal balance in degenerative cervical spine: an analysis using kinematic MRI. Spine (Phila Pa 1976). 2016;41(3):185-190

14. Akbar M, Almansour H, Lafage R, et al. Sagittal alignment of the cervical spine in the setting of adolescent idiopathic scoliosis. J Neurosurg Spine. 2018;29(5):506-514.

15. Staub BN, Lafage R, Kim HJ, et al. Cervical mismatch: the normative value of T1 slope minus cervical lordosis and its ability to predict ideal cervical lordosis. J Neurosurg Spine. 2018;30(1):31-37.

16. Lee DH, Ha JK, Chung JH, et al. A retrospective study to reveal the effect of surgical correction of cervical kyphosis on thoraco-lumbo-pelvic sagittal alignment. Eur Spine J. 2016;25(7):2286-2293.

17. Hyun SJ, Kim KJ, Jahng TA, Kim HJ. Relationship between T1 slope and cervical alignment following multilevel posterior cervical fusion surgery: impact of T1 slope minus cervical lordosis. Spine (Phila Pa 1976). 2016;41(7):E396-E402.
18. Bao H, Varghese J, Lafage R, et al. Principal radiographic characteristics for cervical spinal deformity: a healthrelated quality-of-life analysis. Spine (Phila Pa 1976). 2017;42(18):1375-1382.

19. Iyer S, Nemani VM, Nguyen J, et al. Impact of cervical sagittal alignment parameters on neck disability. Spine (Phila Pa 1976). 2016;41(5):371-377.

20. Xing R, Liu W, Li X, et al. Characteristics of cervical sagittal parameters in healthy cervical spine adults and patients with cervical disc degeneration. BMC Musculoskelet Disord. 2018;19(1):37.

\section{Disclosures}

This project was funded by a grant from Medtronic (ERP-201711052 to G.A.J., the primary investigator), which provided financial support to cover the cost of materials. Dr. Muriuki reports receiving research support from International Surgical SECZ.

\section{Author Contributions}

Conception and design: Jones, Hofler, Havey, Blank, Patwardhan. Acquisition of data: Jones, Hofler, Muriuki, Havey, Blank, Patwardhan. Analysis and interpretation of data: Jones, Hofler, Muriuki, Havey, Blank, Patwardhan. Drafting the article: all authors. Critically revising the article: all authors. Reviewed submitted version of manuscript: Jones, Hofler, Muriuki, Frazzetta. Approved the final version of the manuscript on behalf of all authors: Jones. Statistical analysis: Muriuki, Havey, Blank. Administrative/technical/material support: Jones, Hofler, Blank, Frazzetta, Patwardhan. Study supervision: Jones, Hofler, Blank, Frazzetta, Patwardhan.

\section{Correspondence}

G. Alexander Jones: Loyola University Stritch School of Medicine, Maywood, IL. alexander.jones@lumc.edu. 